\title{
Changes in peri-ocular anatomy and physiology in pseudoexfoliation syndrome (Review)
}

\author{
EFSTATHIOS T. DETORAKIS ${ }^{1}$, GEORGIOS BONTZOS ${ }^{2}$, \\ ELENI E. DRAKONAKI ${ }^{3}$ and DEMETRIOS A. SPANDIDOS ${ }^{4}$
}

\begin{abstract}
${ }^{1}$ Department of Ophthalmology, University Hospital of Heraklion, Heraklion 71110; ${ }^{2}$ Department of Ophthalmology, Red Cross Hospital, Athens 11526, Greece; ${ }^{3}$ Department of Anatomy, Medical School, European University of Cyprus, Nicosia 1516, Cyprus; ${ }^{4}$ Laboratory of Clinical Virology, Medical School, University of Crete, Heraklion 71003, Greece
\end{abstract}

Received December 16, 2020; Accepted March 18, 2021

DOI: $10.3892 / \mathrm{etm} .2021 .10082$

\begin{abstract}
Pseudoexfoliation syndrome (PEX) is characterized by the deposition of proteinaceous material in the anterior ocular segment (resulting in ophthalmic pathologies such as glaucoma and increased risk of complications in cataract surgery), but also by several systemic manifestations. The involvement of peri-ocular tissues in PEX, including the eyelid skin, lacrimal gland, conjunctiva, orbital fat and vessels, as well as the optic nerve, has been reported by several previous studies. The peri-ocular effects of PEX include the development of eyelid laxity, conjunctival chalasis, tear film abnormalities, pronounced orbital fat atrophy in response to the administration of prostaglandin analogues in pseudoexfoliative glaucoma, deficient orbital vascular supply and biomechanical changes in both the eyeball and the optic nerve. These effects may have important clinical implications, including increased difficulty in cataract surgery, ocular surface disease and eyelid margin malpositions.
\end{abstract}

\section{Contents}

1. Introduction

2. Epidemiological, pathogenetic and clinical features

3. Extra-ocular manifestations

4. Eyelid skin involvement

5. Tarsal and canthal tendon involvement

6. Conjunctival, ocular surface and lacrimal involvement

7. Orbital involvement

8. Optic nerve changes

9. Clinical implications of peri-ocular involvement in PEX

10. Conclusions

Correspondence to: Dr Efstathios T. Detorakis, Department of Ophthalmology, University Hospital of Heraklion, 1 Papanastasiou avenue, Heraklion 71110, Greece

E-mail: detorakis@hotmail.com

Key words: pseudoexfoliation, eyelid, orbit, lacrimal, skin

\section{Introduction}

Pseudoexfoliation syndrome (PEX), first described in 1953 by Dvorak-Theobald (1), is characterized by the diffuse deposition of grey-white flakes in the anterior ocular segment (Fig. 1) without previous exposure to heat (infra-red irradiation), as opposed to true exfoliation, in which the eye has been exposed to high heat, often as an occupational hazard (such as in glassblowers, blacksmiths or bakers) (2). The latter, first described in 1922 by Elschnig (2), is characterized by the deposition of material on the anterior lens surface, frequently in the form of a distinct circular flap, the so-called double-ring sign or capsulorrhexis masquerade (3). In PEX, the accumulated material possibly results from a disturbed basal membrane metabolism and is similar to amyloid (4). Several previous studies have reported the detection of pseudoexfoliative material in various extra-ocular sites, giving rise to the concept that PEX is actually a systemic disease, with multi-organ clinical implications $(5,6)$. The present review focuses on the peri-ocular manifestations of PEX, their importance in clinical management of affected patients and as indicators of the disease.

\section{Epidemiological, pathogenetic and clinical features}

PEX is relatively more prevalent in the areas of Scandinavia, the Mediterranean basin and the Arab world (7). It is also an age-related condition with a slight female predominance (8). Although exposure to increased amounts of ultraviolet (UV) radiation may in part explain this geographic distribution, other factors, such as genetic predisposition, auto-immunity or viral infections (including slow-acting viruses or Herpes simplex infections) may also have pathogenetic roles (9-11). Indeed, there have been reports of an increased immunoreactivity in PEX and PEX-related glaucoma, in comparison with age- and gender-matched controls (12). Mutations on the lysil-oxidase-like 1 (LOXL1) gene have been proposed as a risk factor for PEX, whereas caffeine intake and vitamin deficiency may also be involved in the pathogenesis of PEX (13). Genome-wide association studies employing a DNA-pooling approach have explored the potential role of genetic variants in PEX and have reported associations with several single-nucleotide polymorphisms in various genes, apart 
from those in the LOXL1 gene, including other genes such as: OR11L1, CD80, TNIK, CADM2, SORBS2, RNF180, FGF14, FMN1 and RBFOX1, implying that neuronal development and actin remodeling are potentially involved in the pathogenesis of PEX (14).

The importance in PEX diagnosis, as confirmed by clinical examination, from an ophthalmological standpoint, lies in the fact that it has been correlated with several ophthalmic pathologies, more importantly glaucoma, age-related macular degeneration and complications of anterior ocular segment surgery (15-17). Pseudoexfoliative glaucoma is an aggressive form of open-angle glaucoma, frequently displaying non-linear progression and necessitating surgical intervention for adequate intraocular pressure control (18), whereas poor mydriasis, Zinn zonule instability and floppy iris behavior are frequent causes of complications in cataract surgery performed on eyes with PEX (Fig. 2) (17).

\section{Extra-ocular manifestations}

Of note, pseudoexfoliative material or associated abnormalities have been detected in several extra-ocular sites, such as visceral organs (including the lung, heart, liver, kidneys and gallbladder) (19), vascular tissue $(20,21)$ and the brain (22). Based on these observations, it has been suggested that PEX is a systemic condition, which may cause functional disturbances at the affected sites $(5,6)$. So far, associations between PEX and various systemic pathologies have been described, including acoustic impairment (evaluated by both audiometric and tympanometric examinations) (23), obstructive sleep apnea (24), chronic obstructive pulmonary disease (25), indirect inguinal hernia (26) and pelvic organ prolapse in female patients (27). One of the most intriguing clinical associations described is the potential connection between PEX and Alzheimer's disease (AD) $(28,29)$. Although there have been reports linking the 2 entities based on epidemiological and clinical observations, a 30-year population-based study has failed to confirm this hypothesis (28). However, converging evidence points towards biochemical and genetic similarities between PEX and so-called conformational diseases, which are characterized by the accumulation of abnormal proteinaceous amyloid-like material and include AD, Parkinson's disease and amyotrophic lateral sclerosis (29-32).

\section{Eyelid skin involvement}

Previous studies have reported the detection of PEX material in biopsies from eyelid skin and have suggested that peri-ocular skin changes may actually precede the development of frank intra-ocular PEX (33). Periocular skin is particularly susceptible to senile degenerative changes due to the fact that it is thin, undergoes constant mechanical stress associated with blinking movements and, more importantly, it is exposed to the oxidative effects of UV solar radiation (34). Exposure to UV light results in the activation of degrading enzymes from cutaneous lysosomes such as cathepsin K (a potent elastase), resulting in photo-aging and age-related elastosis (35). In fact, epidermal photo-desquamation depends on two distinct proteolytic activities, one of which is an analogue of chymotrypsin and the other one is cathepsin D, with corresponding

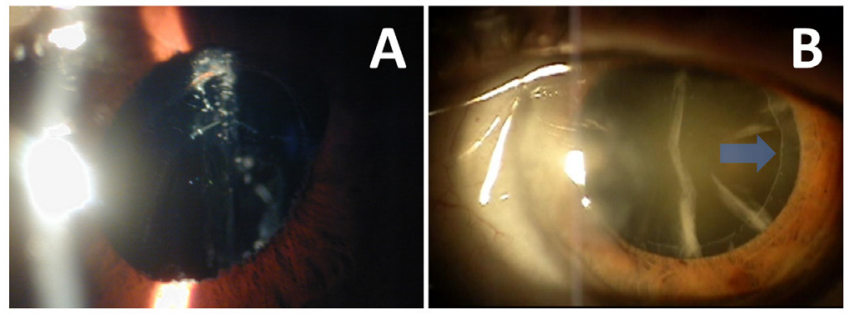

Figure 1. Characteristic appearance of pseudoexfoliation syndrome in the anterior ocular segment in a 75-year-old male patient. (A) Whitish flakes of pseudoexfoliative material visible in the pupillary plane. (B) Deposition of the material in the form of a membrane on the anterior lens capsule (blue arrow).

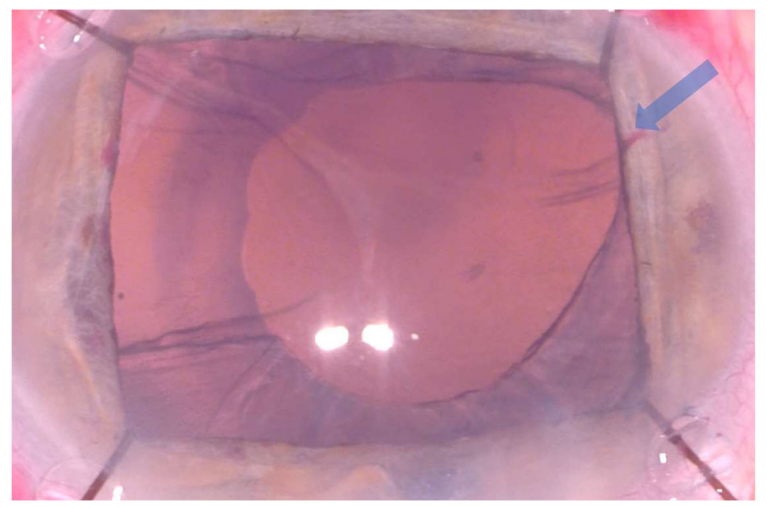

Figure 2. Inadequate intraoperative mydriasis in cataract surgery of an eye with PEX in a 87-year-old female patient, necessitating the use of iris hooks to enhance pupil dilatation. Despite this measure, a posterior capsular rupture occurred in this case (blue arrow), a frequently occurring complication during cataract surgery in eyes with PEX. Magnification, x18. PEX, pseudoexfoliation syndrome.

proteinases being the stratum corneum chymotryptic enzyme and the mature active form of cathepsin D (36). Such skin changes have also been associated with PEX, which shares common confounders with senile eyelid skin elastosis, such as advanced age and exposure to UV radiation (37).

\section{Tarsal and canthal tendon involvement}

The accumulation of pseudoexfoliative material in the peri-ocular connective tissues includes the medial and lateral canthal tendons, tarsal plates and orbicularis oculi muscle $(33,38)$. A study has reported that PEX may be associated with atonic changes of the orbicularis oculi and compromise the stability of medial and lateral canthal tendons, resulting in horizontal and vertical lid laxity and predisposing to the development of eyelid margin malpositions, such as entropion or ectropion (Fig. 3) (38). Furthermore, the tarsal attachments of the lower eyelid retractors may be weakened. On the other hand, PEX has not been associated with upper eyelid ptosis, possibly due to the fact that the upper eyelid retractors (levator palpebrae superioris, Muller's muscle) are comparatively stronger structures that are less likely to be affected by PEX fibrilopathy (38). Alteration in the anatomical stability of peri-ocular connective tissue elements complies with reports for similar extra-ocular changes, such as inguinal hernias (26) or pelvic organ prolapse in female patients (27). 


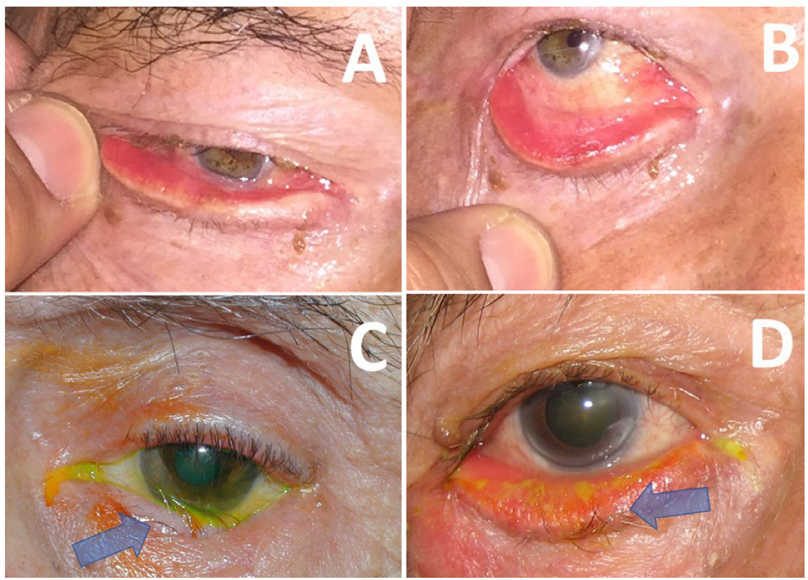

Figure 3. Horizontal and vertical eyelid laxity in the presence of pseudoexfoliation syndrome. (A) Lateral traction test and (B) pinch test from a 68 -year-old male patient. Eyelid laxity in the presence of pseudoexfoliation syndrome predisposes to the patient to eyelid margin malpositions, such as (C) inward rotation (entropion) from a 83-year-old female patient or (D) outward rotation (ectropion) from an 71-year-old male patient, both shown with blue arrows.

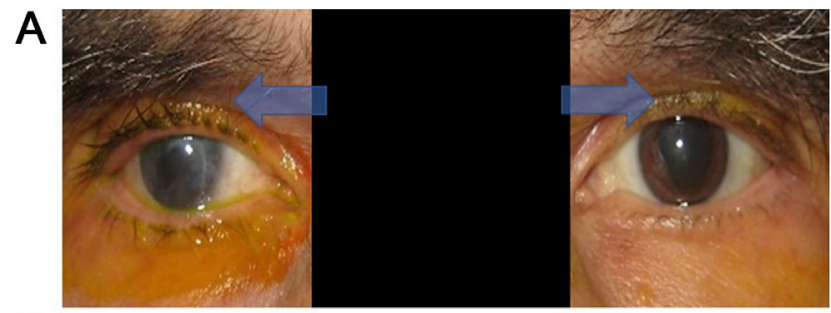

B

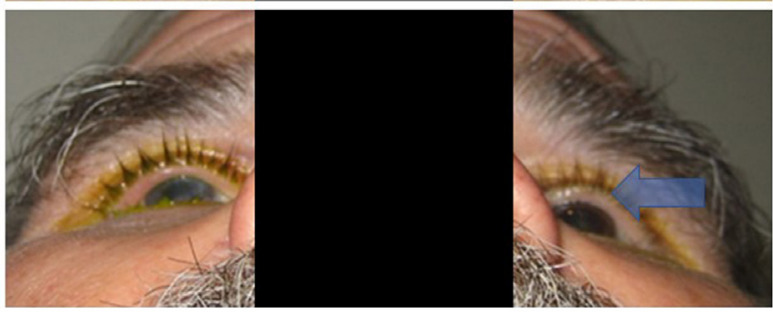

Figure 4. Periocular fat atrophy. (A) Fat atrophy with deepening of the superior palpebral sulcus (blue arrows) in a 69-year-old male patient with pseudoexfoliation syndrome glaucoma under treatment with bimatoprost (blue arrows). (B) Associated enophthalmos (retro-grade displacement of the globe), more pronounced in the left eye of the same patient (blue arrow), visible when examining from an inferior point of view.

\section{Conjunctival, ocular surface and lacrimal involvement}

As in the case of eyelid skin and tendinous anatomical elements of the peri-ocular area, the conjunctiva has also been reported to be affected in PEX, resulting in conjunctival chalasis (39) and subsequent development or deterioration of pre-existing ocular surface disease (OSD). The latter is a chronic malfunction of the physiological elements, contributing to the effectiveness of the ocular surface in supporting eyeball integrity and preserving visual function (40). It has been associated with several pathogenetic mechanisms, including Dry Eye Disease (DED), drug toxicity, particularly from anti-glaucomatous medications, and viral infections, such as the human papillomavirus (40,41). Growing evidence has suggested that PEX may also be involved through combined pathological effects
A

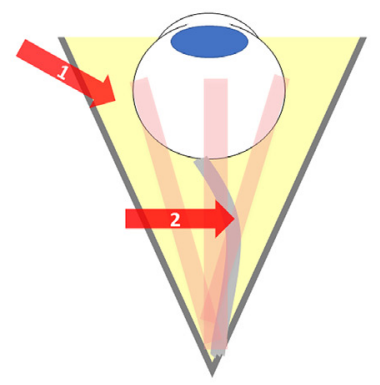

B

Figure 5. Schematic representation of periocular in pseudoexfoliation syndrome. (A) Orbital changes include orbital fat atrophy and enophthalmos (red arrow 1) and biomechanical changes in optic nerve and orbital vasculature (red arrow 2). (B) Eyelid, lacrimal and conjunctival changes include conjunctival chalasis and lacrimal deficiency (red arrows 3) and horizontal and vertical eyelid laxity (red arrows 4).

on all layers, including the tear film, corneal and conjunctival epithelium, as well as eyelid apposition to the eyeball (38). PEX has been reported to be implicated in OSD by several previous studies $(40,42)$. Of note, PEX has been reported to compromise both the quality and quantity of the tear film, as indicated by the defective Schirmer, tear break-up time and tear osmolarity tests (42-45), as well as defective conjunctival goblet cell activity (46), contributing to the development of DED.

\section{Orbital involvement}

The presence of PEX material in the orbits has been reported by several previous studies $(4,47)$. Orbital fat pads, particularly those of the superior eyelid, may be particularly susceptible to atrophic changes induced by bimatoprost (frequently administered as an anti-glaucomatous medication in pseudoexfoliative glaucoma), resulting in enophthalmos (Fig. 4) (48). Apart from the detection of pseudoexfoliative material in the orbital soft tissues, the effect of PEX is particularly pronounced in the orbital vasculature $(49,50)$. Reduced end-diastolic blood velocity at the long posterior ciliary arteries (measured by color Doppler ultrasound imaging) has been detected in eyes with PEX compared with that in normal eyes or even eyes with primary open-angle glaucoma (POAG), implying PEX-induced ischemic stress at the anterior ocular segment (51). Such hemodynamic and hemorheological changes may have important roles in the pathogenesis and clinical course of pseudoexfoliative glaucoma $(49,51)$.

\section{Optic nerve changes}

The importance of studying the potential detrimental effects of PEX on the optic nerve is due to its connection with a particularly aggressive form of glaucoma (pseudoexfoliative glaucoma) (17). The adverse effects of PEX on the optic nerve blood supply are supported by findings of reduced optic nerve head vessel density and reduced peri-papillary capillary vessel density in PEX compared to eyes not affected by PEX (52-54). Of note, PEX may also affect the biomechanical behavior of both anterior and posterior ocular segments (including the peri-papillary sclera and lamina cribrosa) $(55,56)$, which may offer potential explanatory mechanisms for the connection between PEX and glaucoma (57). Biomechanical changes 
of the optic nerve per se have also been reported by a study applying ultrasound elastography, which detected different strain ratios of orbital fat to the optic nerve head in glaucoma patients with PEX as compared with those in the POAG and control groups, implying that such changes may be involved in the pathogenesis of pseudoexfoliative glaucoma (58).

\section{Clinical implications of peri-ocular involvement in PEX}

The effects of PEX material accumulation in peri-ocular tissues may be important concerning the clinical management of affected patients (Fig. 5). Apart from the risks for cataract surgery associated with intraocular PEX, enophthalmic changes (the so-called 'deep-set eyes') due to the use of prostaglandin analogues (particularly bimatoprost), frequently administered in pseudoexfoliative glaucoma, may be an additional source of surgical difficulty and potential intra-operative complications. Eyelid laxity, often resulting in changes of the eyelid margin position such as entropion or ectropion, as well as in lacrimal deficiencies, such as DED or OSD, may also be a source of both intra-operative and post-operative complications in cataract or other forms of intra-ocular surgery in the presence of PEX. Such changes may be more detrimental on the ocular surface, taking into account the reported mechanical corneal sensitivity defects in PEX (59).

\section{Conclusions}

The PEX enigma has yet to be unraveled in the field of Ophthalmology. However, there is growing evidence connecting PEX with other systemic diseases, particularly neurological conditions, associated with tissue and cellular deposition of altered proteinaceous material, such as AD. Several studies have indicated peri-ocular tissue involvement in PEX, including the eyelid skin, tarsus, canthal ligaments, lacrimal secretions, orbital soft tissue, orbital vasculature and optic nerve. Apart from the intraocular clinical effects of PEX, which have been comparatively more extensively studied, the peri-ocular tissues may also have an important clinical role in the overall management of patients with PEX.

\section{Acknowledgements}

Not applicable.

\section{Funding}

No funding was received.

\section{Availability of data and materials}

Not applicable.

\section{Authors' contributions}

ETD, DAS and GB conceptualized the study. ETD and GB wrote and prepared the draft of the manuscript. EED and DAS provided critical revisions. ETD and GB drew the figures. All authors contributed to manuscript revision and approved the final version of the manuscript.

\section{Ethics approval and consent to participate}

Not applicable.

\section{Patient consent for publication}

Not applicable.

\section{Competing interests}

DAS is the Editor in Chief for the journal, but had no personal involvement in the reviewing process, or any influence in terms of adjudicating on the final decision, for this article. The other authors declare that they have no competing interests.

\section{References}

1. Dvorak-Theobald G: Pseudoexfoliation of the lens capsule: Relation to true exfoliation of the lens capsule as reported in the literature, and role in the production of glaucoma capsulocuticulare. Trans Am Ophthalmol Soc 51: 385-407, 1953.

2. Elschnig A: A Detachment of the zonular lamellae in glassblowers. Klin Monatsbl Augenheilkd 69: 732-734, 1922.

3. Braude LS and Edward DP: Partial splitting of the anterior lens capsule giving a ‘double-ring' sign. Arch Ophthalmol 113: 705-708, 1995.

4. Ritch R and Schlötzer-Schrehardt U: Exfoliation syndrome. Surv Ophthalmol 45: 265-315, 2001.

5. Naumann GO, Schlötzer-Schrehardt U and Küchle M: Pseudoexfoliation syndrome for the comprehensive ophthalmologist. Intraocular and systemic manifestations. Ophthalmology 105: 951-968, 1998.

6. Schlötzer-Schrehardt UM, Koca MR, Naumann GOH and Volkholz H: Pseudoexfoliation syndrome. Ocular manifestation of a systemic disorder? Arch Ophthalmol 110: 1752-1756, 1992.

7. Bialasiewicz AA, Wali U, Shenoy R and Al-Saeidi R: Patients with secondary open-angle glaucoma in pseudoexfoliation (PEX) syndrome among a population with high prevalence of PEX. Clinical findings and morphological and surgical characteristics. Ophthalmologe 102: 1064-1068, 2005 (In German).

8. Kozart DM and Yanoff M: Intraocular pressure status in 100 consecutive patients with exfoliation syndrome. Ophthalmology 89: 214-218, 1982.

9. Damji KF, Bains HS, Stefansson E, Loftsdottir M, Sverrisson T, Thorgeirsson E, Jonasson F, Gottfredsdottir M and Allingham RR: Is pseudoexfoliation syndrome inherited? A review of genetic and nongenetic factors and a new observation. Ophthalmic Genet 19: 175-185, 1998.

10. Kozobolis VP, Detorakis ET, Sourvinos G, Pallikaris IG and Spandidos DA: Loss of heterozygosity in pseudoexfoliation syndrome. Invest Ophthalmol Vis Sci 40: 1255-1260, 1999.

11. Detorakis ET, Kozobolis VP, Pallikaris IG and Spandidos DA: Detection of herpes simplex virus in pseudoexfoliation syndrome and exfoliation glaucoma. Acta Ophthalmol Scand 80: 612-616, 2002.

12. Joachim SC, Wuenschig D, Pfeiffer N and Grus FH: IgG antibody patterns in aqueous humor of patients with primary open angle glaucoma and pseudoexfoliation glaucoma. Mol Vis 13: 1573-1579, 2007.

13. Miglior S and Bertuzzi F: Exfoliative glaucoma: New evidence in the pathogenesis and treatment. Prog Brain Res 221: 233-241, 2015.

14. Zagajewska K, Piątkowska M, Goryca K, Bałabas A, Kluska A, Paziewska A, Pośpiech E, Grabska-Liberek I and Hennig EE: GWAS links variants in neuronal development and actin remodeling related loci with pseudoexfoliation syndrome without glaucoma. Exp Eye Res 168: 138-148, 2018.

15. Kozobolis VP, Detorakis ET, Tsilimbaris M, Siganos DS, Vlachonikolis IG and Pallikaris IG: Crete, Greece glaucoma study. J Glaucoma 9: 143-149, 2000.

16. Kozobolis VP, Detorakis ET, Tsilimbaris MK, Vlachonikolis IG, Tsambarlakis IC and Pallikaris IG: Correlation between age-related macular degeneration and pseudoexfoliation syndrome in the population of Crete (Greece). Arch Ophthalmol 117: 664-669, 1999. 
17. Sangal N and Chen TC: Cataract surgery in pseudoexfoliation syndrome. Semin Ophthalmol 29: 403-408, 2014.

18. Schweitzer C: Pseudoexfoliation syndrome and pseudoexfoliation glaucoma. J Fr Ophtalmol 41: 78-90, 2018 (In French)

19. Streeten BW,LiZY, Wallace RN, Eagle RC Jr and Keshgegian AA: Pseudoexfoliative fibrillopathy in visceral organs of a patient with pseudoexfoliation syndrome. Arch Ophthalmol 110: 1757-1762, 1992.

20. Chung H, Arora S, Damji KF and Weis E: Association of pseudoexfoliation syndrome with cardiovascular and cerebrovascular disease: A systematic review and meta-analysis. Can J Ophthalmol 53: 365-372, 2018

21. Siordia JA, Franco J, Golden TR and Dar B: Ocular Pseudoexfoliation syndrome linkage to cardiovascular disease. Curr Cardiol Rep 18: 61, 2016.

22. Zikou AK, Kitsos G, Astrakas LG, Xydis VG, Spiliopoulos K, Bagli E and Argyropoulou MI: Pseudoexfoliation syndrome without glaucoma: White matter abnormalities detected by conventional MRI and diffusion tensor imaging. Eur J Radiol 99 82-87, 2018.

23. Detorakis ET, Chrysochoou F, Paliobei V, Konstas AG, Daniilidis V, Balatsouras D, Kefalidis G and Kozobolis VP: Evaluation of the acoustic function in pseudoexfoliation syndrome and exfoliation glaucoma: Audiometric and tympanometric findings. Eur J Ophthalmol 18: 71-76, 2008

24. Shumway C, Curtin K, Taylor S, Sundar KM, Wirostko BM and Ritch R: Association between Obstructive Sleep Apnea and Exfoliation Syndrome: The Utah Project on Exfoliation Syndrome. Ophthalmol Glaucoma: Sep 30, 2020 (Epud ahead of print).

25. Taylor SC, Bernhisel AA, Curtin K, Allingham RR, Ritch R and Wirostko BM: Association between Chronic Obstructive Pulmonary Disease and Exfoliation Syndrome: The Utah Project on Exfoliation Syndrome. Ophthalmol Glaucoma 2: 3-10, 2019.

26. Besch BM, Curtin K, Ritch R, Allingham RR and Wirostko BM: Association of Exfoliation Syndrome With Risk of Indirect Inguinal Hernia: The Utah Project on Exfoliation Syndrome. JAMA Ophthalmol 136: 1368-1374, 2018.

27. Wirostko BM, Curtin K, Ritch R, Thomas S, Allen-Brady K, Smith KR, Hageman GS and Allingham RR: Risk for Exfoliation Syndrome in Women With Pelvic Organ Prolapse: A Utah Project on Exfoliation Syndrome (UPEXS) Study. JAMA Ophthalmol 134: 1255-1262, 2016.

28. Cumurcu T, Dorak F, Cumurcu BE, Erbay LG and Ozsoy E: Is there any relation between pseudoexfoliation syndrome and Alzheimer's type dementia? Semin Ophthalmol 28: 224-229, 2013.

29. Ekström C and Kilander L: Pseudoexfoliation and Alzheimer's disease: A population-based 30-year follow-up study. Acta Ophthalmol 92: 355-358, 2014

30. Davanger M: On the molecular composition and physico-chemica properties of the pseudo-exfoliation material. Acta Ophthalmo (Copenh) 55: 621-633, 1977.

31. Ziangirova GG and Antonova OV: Local senile ocular amyloidosis in the pathogenesis of open-angle glaucoma and pseudo-exfoliative syndrome. Vestn Ross Akad Med Nauk 2: 40-43, 2003 (In Russian).

32. Reniewska B, Mulak M, Misiuk-Hojło M and Kostuś E: Coexistence of Alzheimer's disease with pseudoexfoliation syndrome PEX. Klin Oczna 106: 107-109, 2004 (In Polish).

33. Schlötzer-Schredhardt U, Küchle M, Dörfler S and Naumann GO: Pseudoexfoliative material in the eyelid skin of pseudoexfoliation-suspect patients: A clinico-histopathological correlation. Ger J Ophthalmol 2: 51-60, 1993.

34. Offret $G$ and Haye C: Senile elastosis of the eyelids and of the conjunctiva. Bull Soc Ophtalmol Fr 4: 263-264, 1959 (In French)

35. Codriansky KA, Quintanilla-Dieck MJ, Gan S, Keady M, Bhawan J and Rünger TM: Intracellular degradation of elastin by cathepsin $\mathrm{K}$ in skin fibroblasts--a possible role in photoaging. Photochem Photobiol 85: 1356-1363, 2009.

36. Horikoshi T, Igarashi S, Uchiwa H, Brysk H and Brysk MM: Role of endogenous cathepsin D-like and chymotrypsin-like proteolysis in human epidermal desquamation. Br J Dermatol 141: 453-459, 1999.

37. Streeten BW, Dark AJ, Wallace RN, Li ZY and Hoepner JA Pseudoexfoliative fibrillopathy in the skin of patients with ocular pseudoexfoliation. Am J Ophthalmol 110: 490-499, 1990.

38. Potemkin VV, Rakhmanov VV, Ageeva EV, Alchinova AS and Meshveliani EV: Pseudoexfoliation syndrome and ocular adnexa. Ophthalmol J 9: 15-21, 2016.
39. Erdoğan H, Arici DS, Toker MI, Arici MK, Fariz G and Topalkara A: Conjunctival impression cytology in pseudoexfoliative glaucoma and pseudoexfoliation syndrome. Clin Exp Ophthalmol 34: 108-113, 2006.

40. Fogagnolo P, Torregrossa G, Tranchina L, Ferreras A, De Cillá S, Labbé A, Figus M, Ottobelli L and Rossetti L: Tear film osmolarity, ocular surface disease and glaucoma: a review. Curr Med Chem 26: 4241-4252, 2019

41. Chalkia AK, Bontzos G, Spandidos DA and Detorakis ET: Human papillomavirus infection and ocular surface disease (Review). Int J Oncol 54: 1503-1510, 2019.

42. Skegro I, Suić SP, Kordić R, Jandroković S, Petriček I, Kuzman T, Kalauz M, Perić S and Masnec S: Ocular surface disease in pseudoexfoliation syndrome. Coll Antropol 39: 43-45, 2015.

43. Kozobolis VP, Detorakis ET, Tsopakis GM and Pallikaris IG: Evaluation of tear secretion and tear film stability in pseudoexfoliation syndrome. Acta Ophthalmol Scand 77: 406-409, 1999.

44. Noori S, Sati A, Moulick PS, Kaushik J, Shankar S and Bose R: Tear film abnormalities in pseudoexfoliation syndrome and normal healthy participants: A comparative analysis. Med J Armed Forces India 76: 303-306, 2020.

45. Öncel BA, Pinarci E and Akova YA: Tear osmolarity in unilateral pseudoexfoliation syndrome. Clin Exp Optom 95: 506-509, 2012.

46. Kozobolis VP, Christodoulakis EV, Naoumidi II, Siganos CS, Detorakis ET and Pallikaris LG: Study of conjunctival goblet cell morphology and tear film stability in pseudoexfoliation syndrome. Graefes Arch Clin Exp Ophthalmol 242: 478-483, 2004.

47. Ringvold A: On the occurrence of pseudo-exfoliation material in extrabulbar tissue from patients with pseudo-exfoliation syndrome of the eye. Acta Ophthalmol (Copenh) 51: 411-418, 1973

48. Aydin S, Issikligil I, Tekșen YA and Kir E: Recovery of orbital fat pad prolapsus and deepening of the lid sulcus from topical bimatoprost therapy: 2 case reports and review of the literature. Cutan Ocul Toxicol 29: 212-216, 2010.

49. Galassi F, Giambene B and Menchini U: Ocular perfusion pressure and retrobulbar haemodynamics in pseudoexfoliative glaucoma. Graefes Arch Clin Exp Ophthalmol 246: 411-416, 2008.

50. Dayanir V, Topaloğlu A, Ozsunar Y, Keceli M, Okyay P and Harris A: Orbital blood flow parameters in unilateral pseudoexfoliation syndrome. Int Ophthalmol 29: 27-32, 2009.

51. Detorakis ET, Achtaropoulos AK, Drakonaki EE and Kozobolis VP: Hemodynamic evaluation of the posterior ciliary circulation in exfoliation syndrome and exfoliation glaucoma. Graefes Arch Clin Exp Ophthalmol 245: 516-521, 2007.

52. Sekeroglu MA, Irkec M, Mocan MC, Ileri E, Dikmenoglu N, Seringec N, Karaosmanoglu D and Orhan M: The association of ocular blood flow with haemorheological parameters in primary open-angle and exfoliative glaucoma. Acta Ophthalmol 89: 429-434, 2011

53. Simsek M, Kocer AM, Cevik S, Sen E and Elgin U: Evaluation of the optic nerve head vessel density in the patients with asymmetric pseudoexfoliative glaucoma: An OCT angiography study. Graefes Arch Clin Exp Ophthalmol 258: 1493-1501,2020.

54. Goker YS and Kiziltoprak H: Quantitative analysis of radial peripapillary capillary plexuses in patients with clinically unilateral pseudoexfoliation syndrome. Graefes Arch Clin Exp Ophthalmol 258: 1217-1225, 2020.

55. GrammenandiE,Detorakis ET,Pallikaris IG and Tsilimbaris MK Differences between Goldmann Applanation Tonometry and Dynamic Contour Tonometry in pseudoexfoliation syndrome. Clin Exp Ophthalmol 38: 444-448, 2010.

56. Braunsmann C, Hammer CM, Rheinlaender J, Kruse FE, Schäffer TE and Schlötzer-Schrehardt U: Evaluation of lamina cribrosa and peripapillary sclera stiffness in pseudoexfoliation and normal eyes by atomic force microscopy. Invest Ophthalmol Vis Sci 53: 2960-2967, 2012.

57. Ritch R, Schlötzer-Schrehardt U and Konstas AG: Why is glaucoma associated with exfoliation syndrome? Prog Retin Eye Res 22: 253-275, 2003

58. Unal O, Caglayan M, Kosekahya P, Yulek F and Taslipinar G: Evaluation of optic nerve head biomechanical properties in pseudoexfoliation glaucoma with real-time elastography. Curr Med Imaging Rev 15: 637-644, 2019.

59. Detorakis ET, Koukoula S, Chrisohoou F, Konstas AG and Kozobolis VP: Central corneal mechanical sensitivity in pseudoexfoliation syndrome. Cornea 24: 688-691, 2005.

This work is licensed under a Creative Commons Attribution-NonCommercial-NoDerivatives 4.0 International (CC BY-NC-ND 4.0) License. 